Article

\title{
A theoretical study of electrocatalytic ammonia synthesis on single metal atom/MXene
}

\author{
Yijing Gao, Han Zhuo, Yongyong Cao, Xiang Sun, Guilin Zhuang, Shengwei Deng, Xing Zhong, \\ Zhongzhe Wei, Jianguo Wang * \\ Institute of Industrial Catalysis, College of Chemical Engineering, State Key Laboratory Breeding Base of Green-Chemical Synthesis Technology, Zhejiang \\ University of Technology, Hangzhou 310032, Zhejiang, China
}

\section{A R T I C L E I N F}

\section{Article history:}

Received 18 September 2018

Accepted 5 November 2018

Published 5 February 2019

\section{Keywords:}

Electrocatalytic ammonia synthesis

Single atom catalyst

MXene

Transition metal

Density functional theory

Overpotential

Gibbs free energy

\begin{abstract}
A B S T R A C T
Electrocatalytic ammonia synthesis under mild conditions is an attractive and challenging process in the earth's nitrogen cycle, which requires efficient and stable catalysts to reduce the overpotential. The $\mathrm{N}_{2}$ activation and reduction overpotential of different $\mathrm{Ti}_{3} \mathrm{C}_{2} \mathrm{O}_{2}$-supported transition metal (TM) (Sc, Ti, V, Cr, Mn, Fe, Co, Ni, Cu, Zn, Mo, Ru, Rh, Pd, Ag, Cd, and Au) single-atom catalysts have been analyzed in terms of the Gibbs free energies calculated using the density functional theory (DFT). The end-on $\mathrm{N}_{2}$ adsorption was more energetically favorable, and the negative free energies represented good $\mathrm{N}_{2}$ activation performance, especially in the presence $\mathrm{Fe} / \mathrm{Ti}_{3} \mathrm{C}_{2} \mathrm{O}_{2}(-0.75 \mathrm{eV})$. The overpotentials of $\mathrm{Fe} / \mathrm{Ti}_{3} \mathrm{C}_{2} \mathrm{O}_{2}, \mathrm{Co} / \mathrm{Ti}_{3} \mathrm{C}_{2} \mathrm{O}_{2}, \mathrm{Ru} / \mathrm{Ti}_{3} \mathrm{C}_{2} \mathrm{O}_{2}$, and $\mathrm{Rh} / \mathrm{Ti}_{3} \mathrm{C}_{2} \mathrm{O}_{2}$ were $0.92,0.89,1.16$, and 0.84 $\mathrm{eV}$, respectively. The potential required for ammonia synthesis was different for different TMs and ranged from 0.68 to $2.33 \mathrm{eV}$. Two possible potential-limiting steps may be involved in the process: (i) hydrogenation of $\mathrm{N}_{2}$ to ${ }^{*} \mathrm{NNH}$ and (ii) hydrogenation of ${ }^{*} \mathrm{NH}_{2}$ to ammonia. These catalysts can change the reaction pathway and avoid the traditional $\mathrm{N}-\mathrm{N}$ bond-breaking barrier. It also simplifies the understanding of the relationship between the Gibbs free energy and overpotential, which is a significant factor in the rational designing and large-scale screening of catalysts for the electrocatalytic ammonia synthesis.
\end{abstract}

(C) 2019, Dalian Institute of Chemical Physics, Chinese Academy of Sciences. Published by Elsevier B.V. All rights reserved.

\section{Introduction}

The methods used for ammonia synthesis have significantly progressed during the last century. Haber-Bosh process [1,2] proposed in the 20th century was a revolution in the synthetic ammonia industry. However, the limitations of the operating temperature of this process is overcome by the fast reaction rates and high equilibrium conversion [3]. Energy consumption and the adverse effects on equipment, caused by rigorous operating conditions, must be considered as well. In this context, electrocatalytic ammonia synthesis is an energy-saving and environmentally benign process, and is gaining increasing attention $[4,5]$. The introduction of electrical energy effectively assists the activation of $\mathrm{N}_{2}$ molecule and changes the reaction pathways. Development of efficient catalysts with good stability and high efficiency plays a very important role in reducing the applied voltage [6].

Electrocatalysts are categorized into several groups, such as those based on metals [7-13], metal oxides [14-16], polymers [17] and other hybrid materials [18,19]. Recently, single atom catalysts [20-24] have been widely used in many electrocatalytic reactions. Li and coauthors [25] have proposed that a sin-

\footnotetext{
* Corresponding author. Tel/Fax: +86-571-88871037; E-mail: jgw@zjut.edu.cn

This work was financially supported by the National Natural Science Foundation of China $(21625604,21776251,21671172,21706229,21878272)$. DOI: 10.1016/S1872-2067(18)63197-3| http://www.sciencedirect.com/science/journal/18722067 | Chin. J. Catal., Vol. 40, No. 2, February 2019
} 
gle transition metal (TM) atom supported on graphitic carbon nitride can result in a new class of low-cost, durable, and efficient oxygen evolution reaction catalysts. In addition, single TM atoms embedded into $\mathrm{MoS}_{2}$ [26], carbon, and carbonitride material $[27,28]$ have been considered as promising catalysts in electrocatalytic ammonia synthesis.

The substrate is a key factor for improving the stability of these single-atom catalysts $[20,29]$. Ideal substrates can distribute single atoms separately and evenly, and thus effectively prevent their aggregation. Pandey et al. [30] have successfully synthesized a new two-dimensional material $\left(\mathrm{Ag} / \mathrm{Ti}_{3} \mathrm{C}_{2} \mathrm{~T}_{x}\right.$ MXene) that has strong interactions between the transition metal and MXenes. Thus, MXene can be a promising substrate. Based on density functional theory (DFT) calculations, Zhou et al. have reported a Ti single atom catalyst for $\mathrm{CO}$ oxidation [31] and $\mathrm{CO}_{2}$ reduction [32]. In addition, $\mathrm{Ag}$ [33], Pt [34], and $\mathrm{Pd}$ [35]/MXene hybrids have been widely applied in electrochemistry. Recently, Wang's group [36] and Li's group [37] have successfully synthesized MXene-based for ammonia synthesis. However, there are a few systematic studies screening MXene-supported catalysts for electrocatalytic ammonia synthesis.

A systematic screening of TMs (Sc, Ti, V, Cr, Mn, Fe, Co, Ni, $\mathrm{Cu}, \mathrm{Zn}, \mathrm{Mo}, \mathrm{Ru}, \mathrm{Rh}, \mathrm{Pd}, \mathrm{Ag}, \mathrm{Cd}$, and $\mathrm{Au}$ ) has been carried out to understand the feasibility of MXene-supported single atom catalysts in ammonia synthesis and develop new electrocatalysts with low overpotential. The Gibbs free energy has been calculated to analyze the reaction paths and the overpotentials of $\mathrm{Fe}, \mathrm{Co}, \mathrm{Ru}$, and $\mathrm{Rh}$ supported on MXene catalysts. The potential-determining step was found to be $\mathrm{N}_{2}+\mathrm{H}^{+} \rightarrow \mathrm{NNH}$ for the four TM/MXene catalysts. Further, we studied the relationship between the Gibbs free energy and overpotential for a series of TM-supported catalysts. The results reveal that different TM atoms have different overpotentials, ranging from 0.68 to 2.33 eV. There were two possible potential-limiting steps: (i) $\mathrm{N}_{2}+\mathrm{H}^{+}$ $\rightarrow \mathrm{NNH}$ and (ii) $\mathrm{NH}_{2}+\mathrm{H}^{+} \rightarrow \mathrm{NH}_{3}$. This work provides a new route for the rational designing and large-scale screening of these catalyst for electrocatalytic ammonia synthesis.

\section{Computational methods}

All the calculations were performed using the Vienna ab-initio Simulation Package (VASP), which is based on DFT $[38,39]$. The exchange-correlation energy was calculated using the generalized gradient approximation and the Perdew, Burke, Ernzerhof $[40,41]$. The effect of core electrons on the valence electron density was determined by The Projector Augmented Wave (PAW) method [42]. The cutoff energy for the plane wave basis sets was $400 \mathrm{eV}$. The convergence threshold of atomic position and cell parameters were set to be $10^{-5} \mathrm{eV}$ in energy and $10^{-2} \mathrm{eV} / \AA ̊ \AA$ in force. For geometric optimizations, the Brillouin zone [43] was sampled by $6 \times 6 \times 1 \mathrm{k}$-points mesh, while the same for electronic structures was sampled by $12 \times 12 \times 1$ k-points mesh. The Van der Waals interaction was calculated by the DFT-D3 method [44]. Fully relaxed $3 \times 3$ supercells were used for all the structures. A vacuum space with thickness more than $20 \AA$ was set to avoid the interactions of the periodic im- ages. The charge density difference was analyzed using the VESTA code [45].

The Gibbs free energy calculation was performed following the work of Nørskov et al. [46]. Under the standard reaction condition, the chemical potential of a proton and electron pair $\left(\mu\left(\mathrm{H}^{+}+\mathrm{e}^{-}\right)\right)$is equal to half that of gaseous hydrogen $\left(\mu\left(\mathrm{H}_{2}\right)\right)$. For each elemental step, the Gibbs free energies $(\Delta G)$ were calculated using the following equation:

$\Delta G=\Delta E_{\mathrm{DFT}}+\Delta \mathrm{ZPE}+\Delta H-T \Delta S+\Delta G_{\mathrm{pH}}+\Delta G_{\mathrm{U}}$.

Here, $E$ is the total energy calculated by VASP, ZPE is the zero-point energy, $H$ and $S$ are the heat capacity and entropy, respectively, and $T$ is equal to $298 \mathrm{~K}$. $G_{\mathrm{pH}}$ and $G_{\mathrm{U}}$ are the contributions from the $\mathrm{pH}$ and electrode potential $(U)$, respectively. $G_{U}$ is defined as

$G_{\mathrm{U}}=-n e U$,

where $n$ is the number of electrons transferred. $G_{\mathrm{pH}}$ is defined as

$G_{\mathrm{pH}}=-k_{\mathrm{B}} T \ln \left[\mathrm{H}^{+}\right]=\mathrm{pH} \times k_{\mathrm{B}} T \ln 10$,

where $k_{\mathrm{B}}$ is the Boltzmann constant. For all the calculations presented here, $\mathrm{pH}$ is set to zero.

The adsorption energies ( $\left.E_{\text {ad }}\right)$ of the different adsorbates were calculated using the expression

$E_{\text {ad }}=E_{\text {total }}-\left(E_{\text {catal }}+E_{\text {mol }}\right)$,

where $E_{\text {total }}$ is the total energy of the slab after adsorption, $E_{\text {catal }}$ is the energy of the bare catalyst, and $E_{\mathrm{mol}}$ is the total energy of the adsorbate molecules, i.e., $\mathrm{N}_{2}$ and $\mathrm{N}_{x} \mathrm{H}_{y}$.

\section{Results and discussion}

\subsection{Structure of $\mathrm{Ti}_{3} \mathrm{C}_{2} \mathrm{O}_{2}$-supported single atom catalyst}

A quintuple-layered conventional bare $\mathrm{Ti}_{3} \mathrm{C}_{2}$ MXene consisting of a carbon layer sandwiched between two Ti layers (Ti-C-Ti-C-Ti) was used. The lattice constants of the optimized structure are $a=b=3.110 \AA$, which are well consistent with the experimentally obtained value of $3.057 \AA$ [47]. Because $\mathrm{Ti}_{3} \mathrm{C}_{2}$ MXenes are chemically exfoliated from the bulk MAX phase by HF $[48,49]$, they are always functionalized by the surface group 0. Fig. 1(a) depicts the four different highly symmetric adsorption sites that have been studied. This includes the top site above the Ti atom (T), the bridge site of the Ti-Ti bond (B), and the two different hollow sites (H1 and H2). Calculations show that the hollow site with Ti center (Fig. 1(b)) is the most energetically favorable. Subsequently, the highly symmetrical single atom adsorption sites are considered to be the most active. All the adsorption energies are listed in Table S1 (Supporting Information). Here, we take $\mathrm{Ru}, \mathrm{Rh}, \mathrm{Fe}$, and Co atoms as example, all of which are placed at the hollow site with $\mathrm{C}$ center, as shown in Fig. 1(c).

\section{2. $N_{2}$ adsorption}

$\mathrm{N}_{2}$ adsorption has been investigated on Fe/MXene, Co/MXene, Ru/MXene, and Rh/MXene. Both end-on and side-on modes of $\mathrm{N}_{2}$ adsorption on the top of a single atom have been examined. Fig. 2 shows that all the $\mathrm{N}_{2}$ molecules prefer to adopt an end-on configuration. $\mathrm{N}_{2}$ chemical adsorp- 

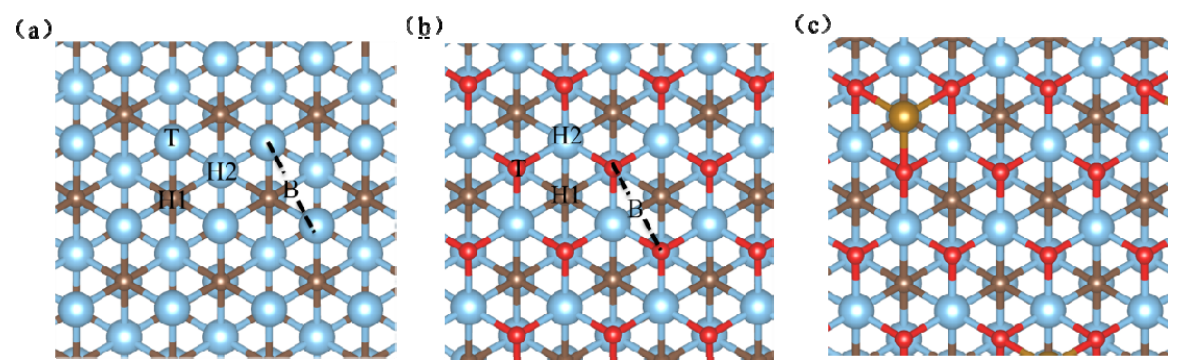

Fig. 1. The schematic illustration of different adsorption sites of (a) $\mathrm{Ti}_{3} \mathrm{C}_{2}$, (b) $\mathrm{Ti}_{3} \mathrm{C}_{2} \mathrm{O}_{2}$, and (c) metal atom/ $\mathrm{Ti}_{3} \mathrm{C}_{2} \mathrm{O}_{2}$. The supercell indicates the high symmetry: top (T), bridge (B), hollow (H1, H2) adatom sites. The blue, brown, red, and orange balls represent Ti, $\mathrm{C}, \mathrm{O}_{2}$, and TM atom, respectively.

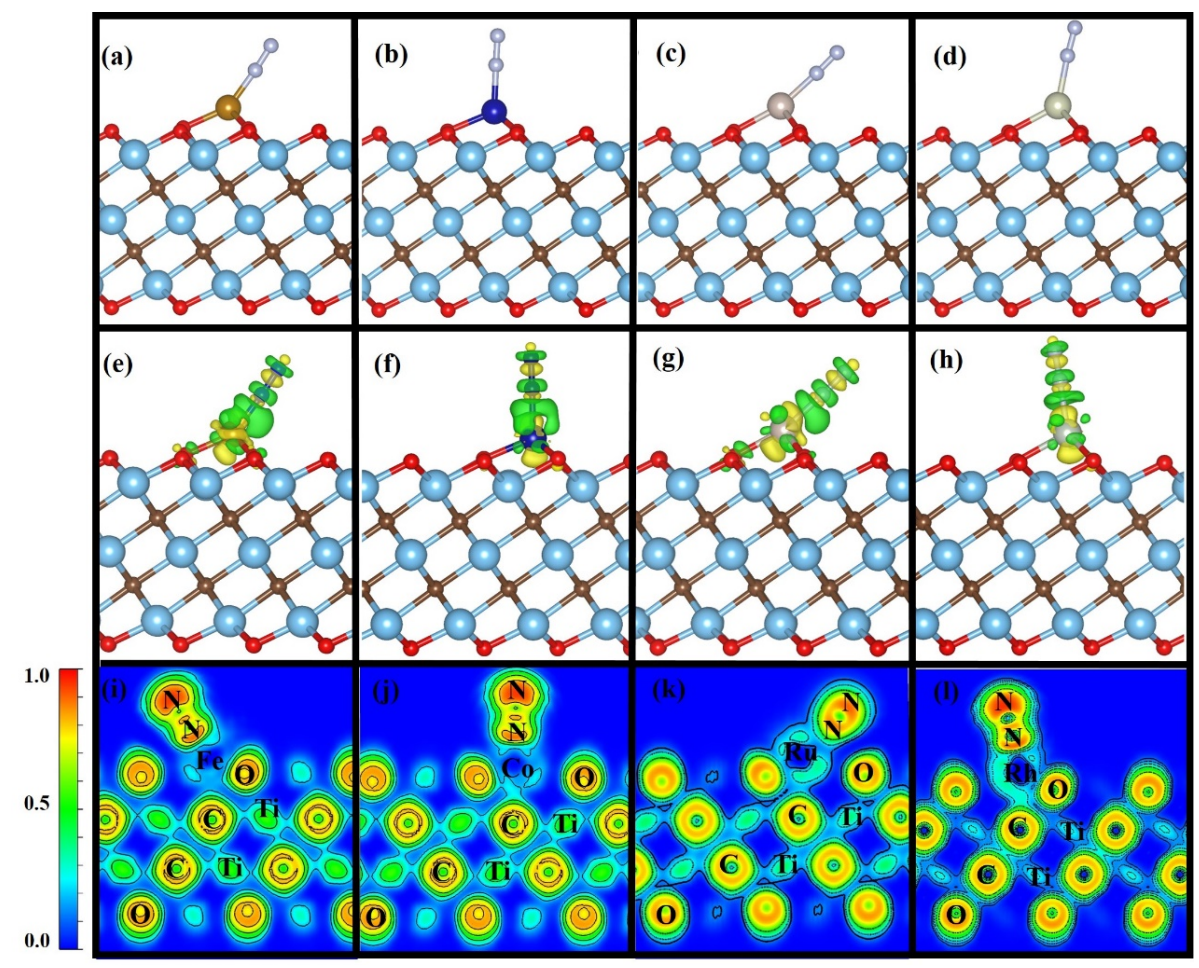

Fig. 2. The most stable structure of $\mathrm{N}_{2}$ adsorbed on (a) Fe/MXene, (b) Co/MXene, (c) Ru/MXene, and (d) Rh/MXene. The distribution of transferred charges between $\mathrm{N}_{2}$ and (e) Fe/MXene, (f) Co/MXene, (g) Ru/MXene, and (h) Rh/MXene catalysts. The isovalues for all of them are equal to 0.005 e $\AA^{-3}$ Green represents the gain of charge while yellow represents the loss of charge. (i), (j), (k), and (l) represent the electron localization function (ELF) plots for the corresponding configurations. The blue, brown, and red balls represent Ti, C, and 0 atoms, respectively. Dark brown, orange, silver, and pink balls represent $\mathrm{Fe}, \mathrm{Co}, \mathrm{Ru}$, and $\mathrm{Rh}$ atom, respectively.

tion has high $E_{\text {ad }}$ values ( -0.65 to $-1.30 \mathrm{eV}$ ), thereby indicating a strong and energetically favorable $\mathrm{N}_{2}$ adsorption (Table S2). The order of $E_{\text {ad }}$ obeys the following trend: Fe/MXene > Co/MXene $>$ Ru/MXene $>$ Rh/MXene. This suggests that Fe has a strong $\mathrm{N}_{2}$-philicity. The $\mathrm{N} \equiv \mathrm{N}$ bond lengths in these four catalysts are $1.134,1.133,1.136$, and $1.128 \AA$, respectively, and are slightly longer than the bond length in gas phase $N_{2}(1.11 \AA)$. Similarly, $\mathrm{N} \equiv \mathrm{N}$ bond length in the $\mathrm{TM} / \mathrm{BN}$ catalyst is around $1.12 \AA ̊$ [27].

ELF analysis [50,51] was carried out to estimate the bond strengths. The value of ELF is set in the range of 0 to 1 , where 1 , 0.5 , and 0 represent covalent, metallic, and nonbonding characters, respectively. Strong ELF, $\sim 0.8$, is observed around $C$ and 0 atoms, while the ELF around Ti atoms was $\sim 0.5$. The localization of electron pairs between $\mathrm{Ti}$ and $\mathrm{C}$ atoms, $\mathrm{O}$ and TM atoms, and $\mathrm{C}$ and $\mathrm{TM}$ atoms indicates a metallic-ionic character (ELF $=$ $\sim 0.3$ ). In addition, there is a weak localization of electrons near the hollow site $(\mathrm{ELF}=\sim 0.3)$ on the surface of $\mathrm{Ti}_{3} \mathrm{C}_{2} \mathrm{O}_{2}$ MXene.

Further, the charge density differences and Bader charge analysis [52] were performed. Green represents the gain of charge, while yellow represents the loss of charge. It can be seen that $\mathrm{N}_{2}$ acts as the electron acceptor, with the electrons being transferred from the TM atom in all the structure. The charge transfer for all the catalysts is very small. For Fe atom, the amount of charge transfer is $0.18 \mathrm{e}$, which is the largest among the four catalysts (Table S3). It can be inferred that greater the charge transfer, the more active is the metal. Consequently, higher the number of electrons gained by $\mathrm{N}_{2}$, better is the activation of the $\mathrm{N}-\mathrm{N}$ bond. This is consistent with the previous calculation.

Furthermore, the partial density of states (PDOS) of $\mathrm{N}_{2}$ adsorption configuration exhibits the $d$ states of TM atoms and $p$ states of $\mathrm{N}$ atom both in the spin-down and spin-up states, as shown in Fig. 3. There is spin polarization in the $\mathrm{TM} / \mathrm{Ti}_{3} \mathrm{C}_{2} \mathrm{O}_{2}$ 
MXene. The $d$ orbitals of TM atoms effectively overlap with $\mathrm{N}$ $2 p$ orbitals near the Fermi level. Consequently, the interaction between $\mathrm{Fe}$ and $\mathrm{N}_{2}$ molecules is the strongest. The electrons in the occupied $d$ orbitals of $\mathrm{Fe} / \mathrm{Ti}_{3} \mathrm{C}_{2} \mathrm{O}_{2}$ MXene were transferred into the antibonding orbitals of $\mathrm{N}_{2}$, thereby resulting in the decrease of the bond order of $\mathrm{N}_{2}$. Thus, Fe exhibits the best $\mathrm{N}_{2}$ activation performance.

\section{3. $\quad N_{2}$ reduction mechanism}

In general, ammonia synthesis may take place via two reaction mechanisms. Based on the $\mathrm{N}_{2}$ bond breaking step, it can be defined as either associative or dissociative mechanism. Considering the probable configurations of $\mathrm{N}_{x} \mathrm{H}_{y}$ species, five possible reaction pathways were investigated.

In Fig. 4, red and purple lines represent the two associative pathways (association A and association B, respectively), while blue, yellow, and black lines represent the dissociative pathways (dissociation $\mathrm{A}$, dissociation $\mathrm{B}$, and dissociation $\mathrm{C}$, respectively). In the association A pathway, protonation occurs on one side of $\mathrm{N}_{2}$ until the first ammonia is released. The second ammonia is generated by three other hydrogenation steps wherein the ${ }^{*} \mathrm{~N}$ species is hydrogenated into ${ }^{*} \mathrm{NH},{ }^{*} \mathrm{NH}_{2}$, and $\mathrm{NH}_{3}$. In the association $\mathrm{B}$ pathway, the second $\mathrm{H}^{+}+\mathrm{e}^{-}$pair attacks the

(a)
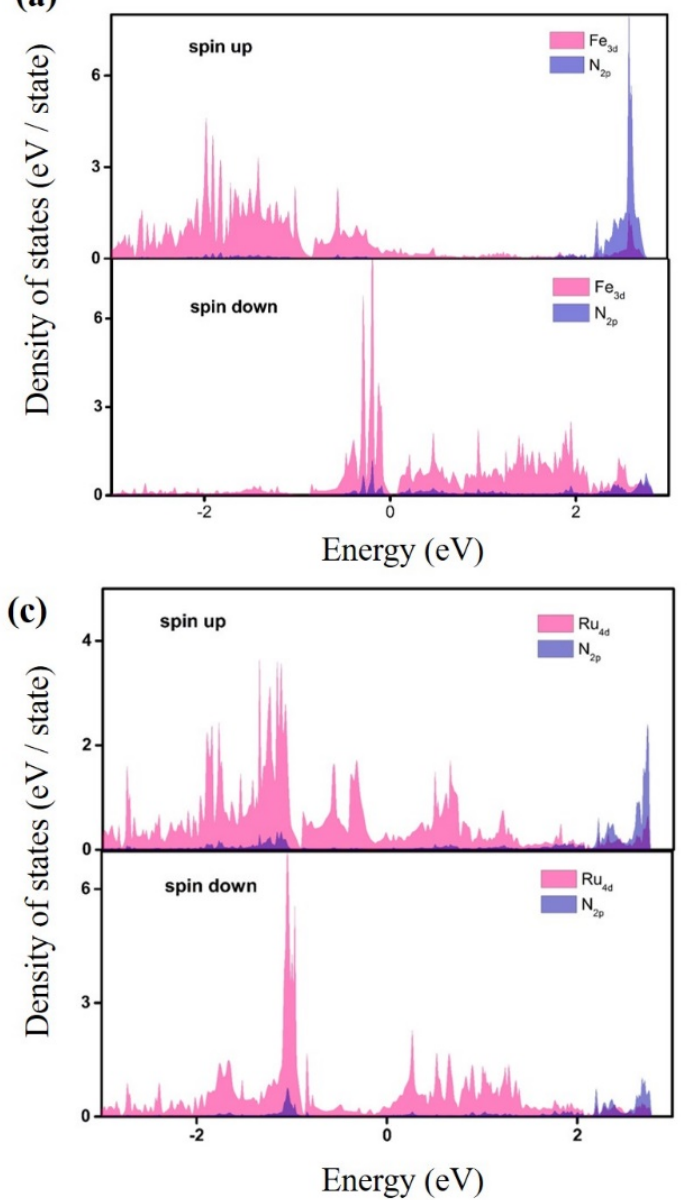

NNH species to form *NHNH species. The following protonation steps are equally probable and generate ${ }^{*} \mathrm{NHNH}_{2}$ and $\mathrm{NH}_{2} \mathrm{NH}_{2}$. The last two steps yield two ammonia molecules, one after the other. In the dissociative pathway, $\mathrm{N}_{2} \mathrm{H}$ separates into $\mathrm{N}$ atom and $\mathrm{NH}$ species after the hydrogenation. The dissociation $\mathrm{A}$ pathway shows that the protonation occurs first on ${ }^{*} \mathrm{NH}$ to form ammonia, followed by the synthesis of the second ammonia, as in association $\mathrm{A}$. The $\mathrm{N}$ atoms of $\mathrm{N}_{2}$ in the dissociation $\mathrm{B}$ pathway are oriented more symmetrically. Protonation preferably yields symmetrical products, such as ${ }^{*} \mathrm{NH}$ and $* \mathrm{NH}$, and ${ }^{*} \mathrm{NH}_{2}$ and ${ }^{*} \mathrm{NH}_{2}$. Dissociation $\mathrm{C}$ pathway generates ${ }^{*} \mathrm{NHNH}_{2}$ species during ${ }^{*} \mathrm{NNH}_{2}$ hydrogenation. The next step is the dissociation into two ${ }^{*} \mathrm{NH}_{2}$ species.

DFT calculations were also carried out to obtain a reasonable approximation of the Gibbs free energy. The correction terms (zero-point energy, enthalpy, temperature, and entropy corrections) of adsorbates and gas-phase molecules are listed in Tables S1 and S2.

The free energy profiles along the most probable pathways are summarized in Fig. 5, and the corresponding atomic configurations along the reaction paths are displayed under the profiles. It can be seen that $\mathrm{Fe}, \mathrm{Co}$, and $\mathrm{Rh}$ have the same reaction pathway. In Fig. 5(a), the first protonation is likely to generate *NNH species, with the Gibbs free energy increasing to

\section{(b)}
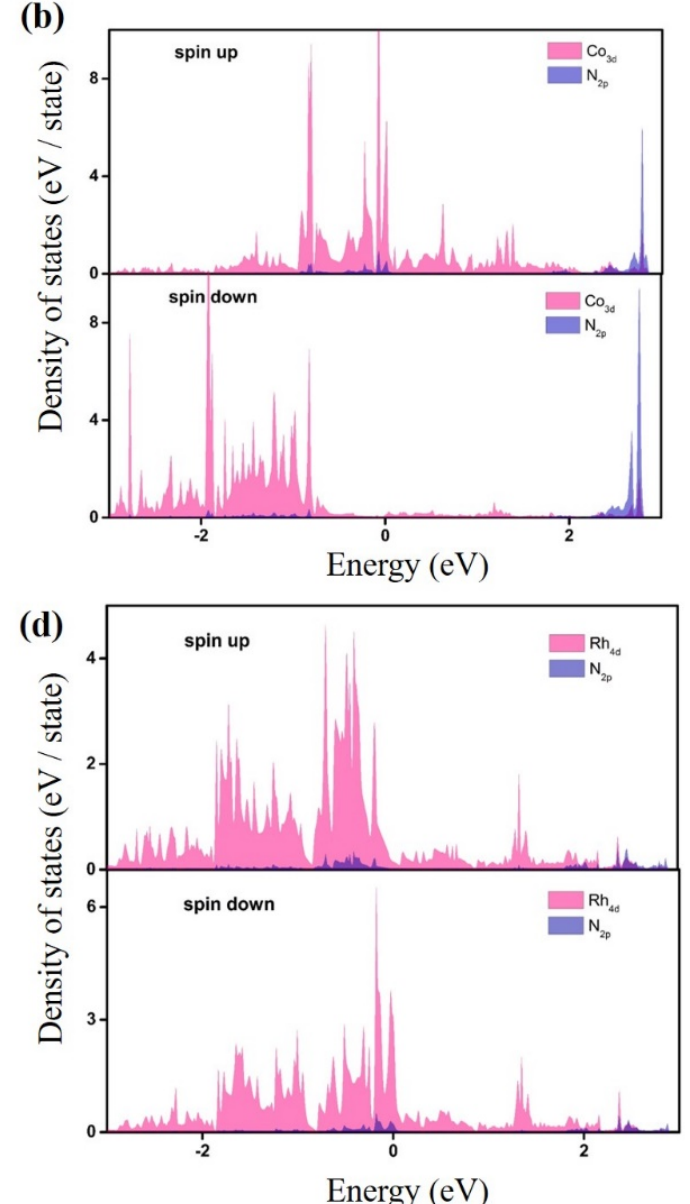

Fig. 3. Partial density of states (PDOS) of $\mathrm{N}_{2}$ adsorbed on (a) Fe/MXene, (b) Co/MXene (c), Ru/MXene, and (d) Rh/MXene. 


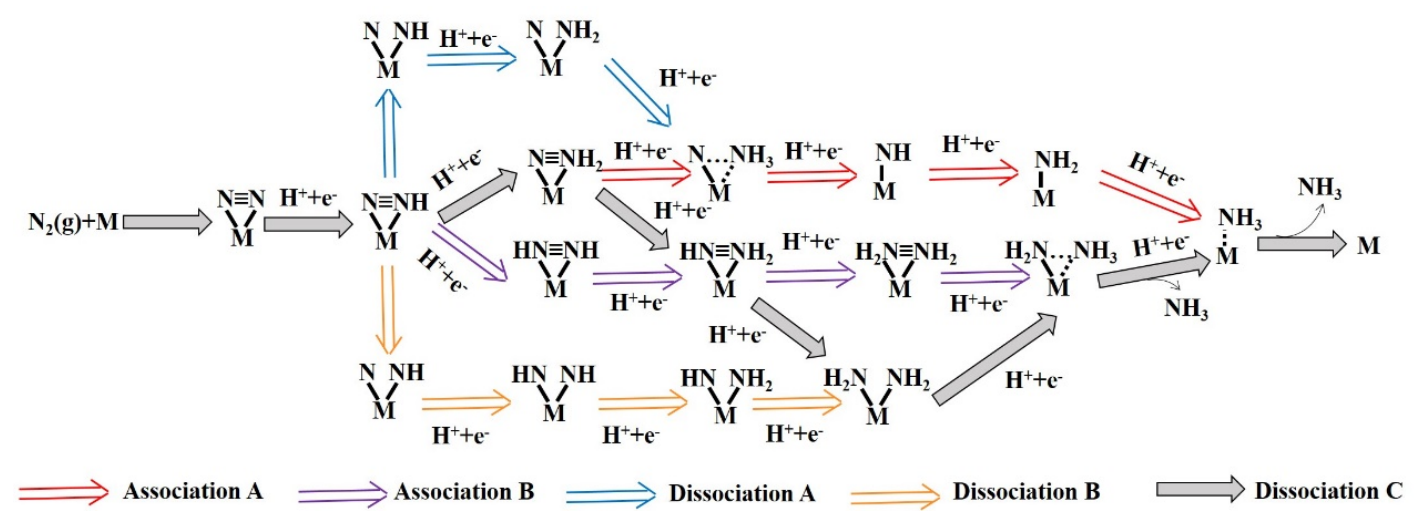

Fig. 4. Schematic representation of the possible pathways and reaction intermediates for NRR.

$0.88 \mathrm{eV}$. The generation of *NNH species is also endothermic with $0.56 \mathrm{eV}$ (Fig. 5(b)). The Gibbs free energy for the first step in the presence of Rh/MXene is $0.80 \mathrm{eV}$ (Fig. 5(d)). The $\Delta G$ value for the second step involving the formation of $* \mathrm{NNH}_{2}$ is 0.19 $\mathrm{eV}$, which is larger than that on Rh/MXenes $(0.07 \mathrm{eV})$. For $\mathrm{Co} / \mathrm{MXene}$ catalyst, the Gibbs free energy for the formation of ${ }^{*} \mathrm{NNH}_{2}$ was slightly smaller $(-0.02 \mathrm{eV})$. All the three steps following this are exothermic, as indicated by the negative Gibbs free energies. The Gibbs free energies of these three steps are $-0.62,-0.45$, and $-0.55 \mathrm{eV}$ for Fe/MXene. The Gibbs free energies for the corresponding steps in Rh/MXene is $-0.60,-0.66$, and $-0.04 \mathrm{eV}$, while those for Co/MXene are $-0.27,-1.03$, and $-0.64 \mathrm{eV}$. The Gibbs free energy for the step involving ammonia synthesis is positive $(0.53 \mathrm{eV})$ in the presence of $\mathrm{Fe} / \mathrm{MXene}$ catalyst, while it is negative in the presence of $\mathrm{Rh} / \mathrm{MXene}(\Delta G=$ $-0.20 \mathrm{eV})$ and Co/MXene $(\Delta G=-0.14 \mathrm{eV})$. The Ru/MXene has a similar pathway. The $\Delta G$ value for the formation of $* \mathrm{NNH}$ is $1.12 \mathrm{eV}$. The second step is the addition of $\mathrm{H}^{+}$into the $-\mathrm{NH}$ terminal to form ${ }^{*} \mathrm{NNH}_{2}$ species $(\Delta G=-0.67 \mathrm{eV})$. In the third step, the triple bond of $\mathrm{N}_{2}$ breaks, and one ammonia is released with a free energy of $-0.83 \mathrm{eV}$. There are three other protonation steps before the second ammonia is formed. The Gibbs free energy of these three steps are $0.34,-0.67$, and $-0.44 \mathrm{eV}$, respectively.

It is also necessary to evaluate the potential-determining step (PDS) and the corresponding minimum overpotential. The
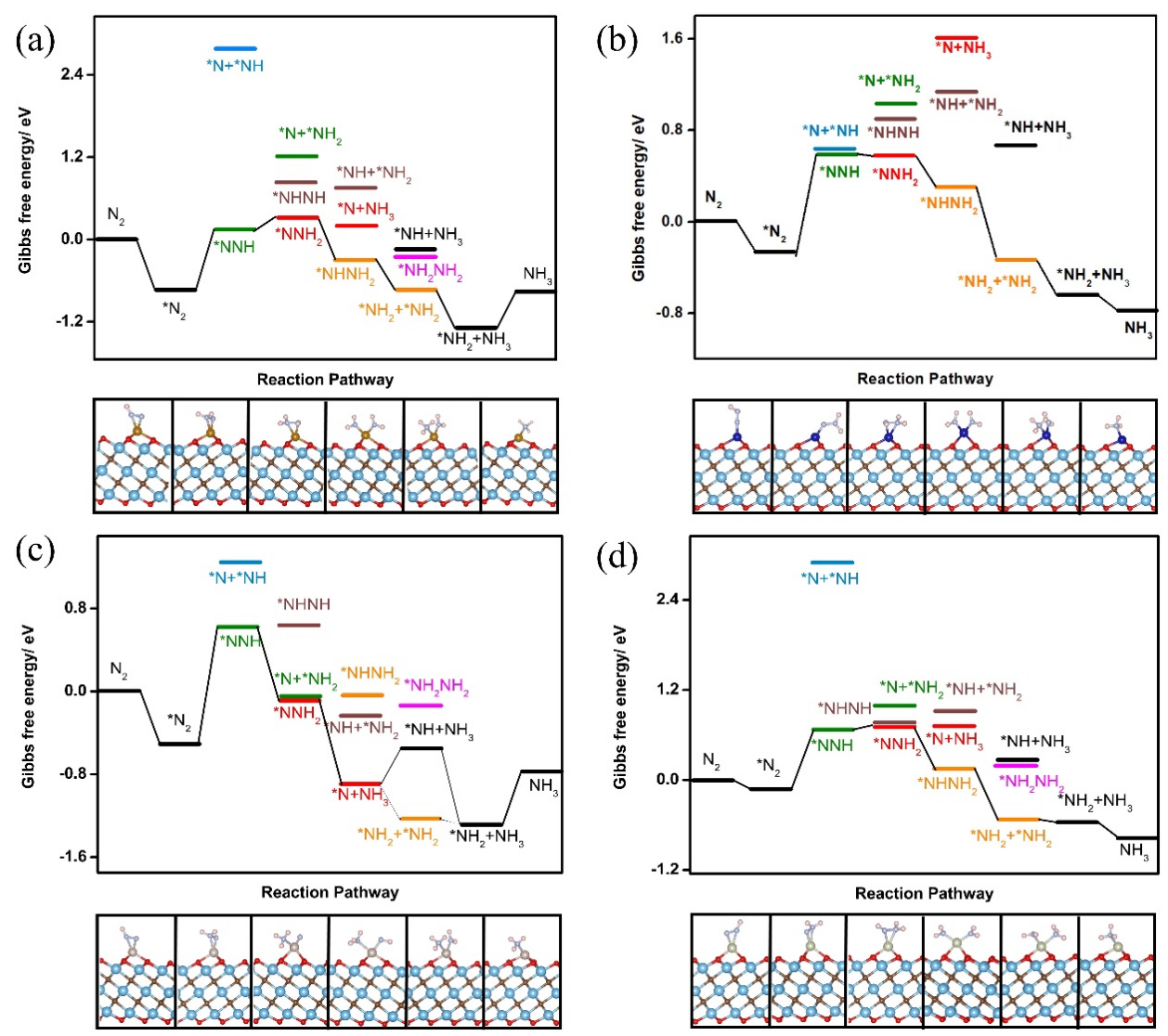

Fig. 5. Gibbs free energy diagrams of (a) Fe/MXene, (b) Co/MXene, (c) Ru/MXene, and (d) Rh/MXene at $U=0 \mathrm{~V}$. 
potential-limiting step of $\mathrm{Fe}, \mathrm{Co}, \mathrm{Rh}$, and $\mathrm{Ru}$ supported on MXene is the hydrogenation of $\mathrm{N}_{2}$ to form ${ }^{*} \mathrm{NNH}$ species. The corresponding overpotentials of these four catalysts are 0.88 , $0.85,0.80$, and $1.12 \mathrm{eV}$, respectively.

\subsection{TM/MXene electrocatalyst for nitrogen reduction reaction (NRR)}

Further, more $3 d / 4 d$ TM supported on MXene catalysts have been synthesized to study the relationship between the overpotential and Gibbs free energy of the potential-limiting step. The most stable $\mathrm{N}_{2}$ adsorption on the TM/ $/ \mathrm{Ti}_{3} \mathrm{C}_{2} \mathrm{O}_{2}$ MXenes has been studied by Gibbs free energy calculations. The $G_{\mathrm{N} 2}$ represents the Gibbs free energy change from the gas phase to ${ }^{*} \mathrm{~N}_{2}$. The results indicate that the side-on $\mathrm{N}_{2}$ adsorption is less energetically favorable than the end-on adsorption (Table S2). Previous studies on $\mathrm{TM} / \mathrm{C}_{2} \mathrm{~N}$ also reported similar results [27]. The negative $\Delta G$ values indicate favorable $\mathrm{N}_{2}$ adsorption on all the studied $3 d \mathrm{TM} / \mathrm{Ti}_{3} \mathrm{C}_{2} \mathrm{O}_{2}$ MXenes, except Sc and Zn (Fig. 6(a)). The late $4 d$ TM-supported MXene, except for Ag, also represents good $\mathrm{N}_{2}$ activation (Fig. 6(c)). In contrast to several single-atom catalysts [53-55], most of the $\mathrm{TM} / \mathrm{Ti}_{3} \mathrm{C}_{2} \mathrm{O}_{2}$ MXenes, and particularly $\mathrm{Fe}$, could sufficiently activate $\mathrm{N}_{2}$ molecules, and thus facilitate their subsequent reduction steps. Fig. 6(b) shows that the overpotentials of $3 d$ TM-supported MXene are between 0.68 and $1.96 \mathrm{eV}$, while those for the late $4 d$ TM-supported MXene are between 0.84 and $2.33 \mathrm{eV}$ (Fig. 6(d)). In addition, overpotential has an inseparable relationship with Gibbs free energy. Calculations show that there are two possible potential-limiting steps: (i) $\mathrm{N}_{2}+\mathrm{H}^{+} \rightarrow \mathrm{NNH}$ and (ii) $\mathrm{NH}_{2}+$
$\mathrm{H}^{+} \rightarrow \mathrm{NH}_{3}$. In the $3 d \mathrm{TM}, \mathrm{Mn} / \mathrm{MX}$ ene has the lowest overpotential and the potential-determining step is $\mathrm{NNH}$ generation with a $\Delta G$ value of $0.68 \mathrm{eV}$. For the $4 d \mathrm{TM}$, Mo/MXene has the lowest overpotential, with the potential-limiting step being the formation of the $\mathrm{NNH}$ with a $\Delta G$ value of $0.84 \mathrm{eV}$. Further, we have also studied the overpotential of $\mathrm{Au} / \mathrm{Ti}_{3} \mathrm{C}_{2} \mathrm{O}_{2}$ by this relationship (Table S6). The results reveal that $\mathrm{Au}$ single atom catalyst has slightly reduced overpotential $(1.74 \mathrm{eV})$ compared to other Au catalyst [56].

According to the previous studies, designing electrocatalysts that can reduce the overpotential of electrocatalytic ammonia synthesis is a challenge. Contrary to the traditional Haber-Bosch process, the $\mathrm{N} \equiv \mathrm{N}$ bond does not break in the $\mathrm{N}_{2}$ activation step on the $\mathrm{TM} / \mathrm{Ti}_{3} \mathrm{C}_{2} \mathrm{O}_{2}$ MXenes. It can be concluded that such catalysts can alter the reaction pathway by effectively avoiding the steps with high energy barrier, which would ultimately reduce the overpotential.

\section{Conclusions}

Reaction paths and overpotentials of $\mathrm{Fe}, \mathrm{Co}, \mathrm{Ru}$, and $\mathrm{Rh}$ supported on MXene catalysts in the electrocatalytic ammonia synthesis have been studied using DFT. Gibbs free energy calculations reveal that the potential-determining step is $\mathrm{N}_{2}+\mathrm{H}^{+}$ $\rightarrow$ NNH for all the four TM/MXene catalyst. Further, we studied the relationship between the Gibbs free energy of the potential-determining steps and overpotential for a series of TM/MXene catalysts. Different TM atoms have different overpotentials, ranging from 0.68 to $2.33 \mathrm{eV}$. Calculations show that there are two possible potential-limiting steps: (i) $\mathrm{N}_{2}+\mathrm{H}^{+} \rightarrow$
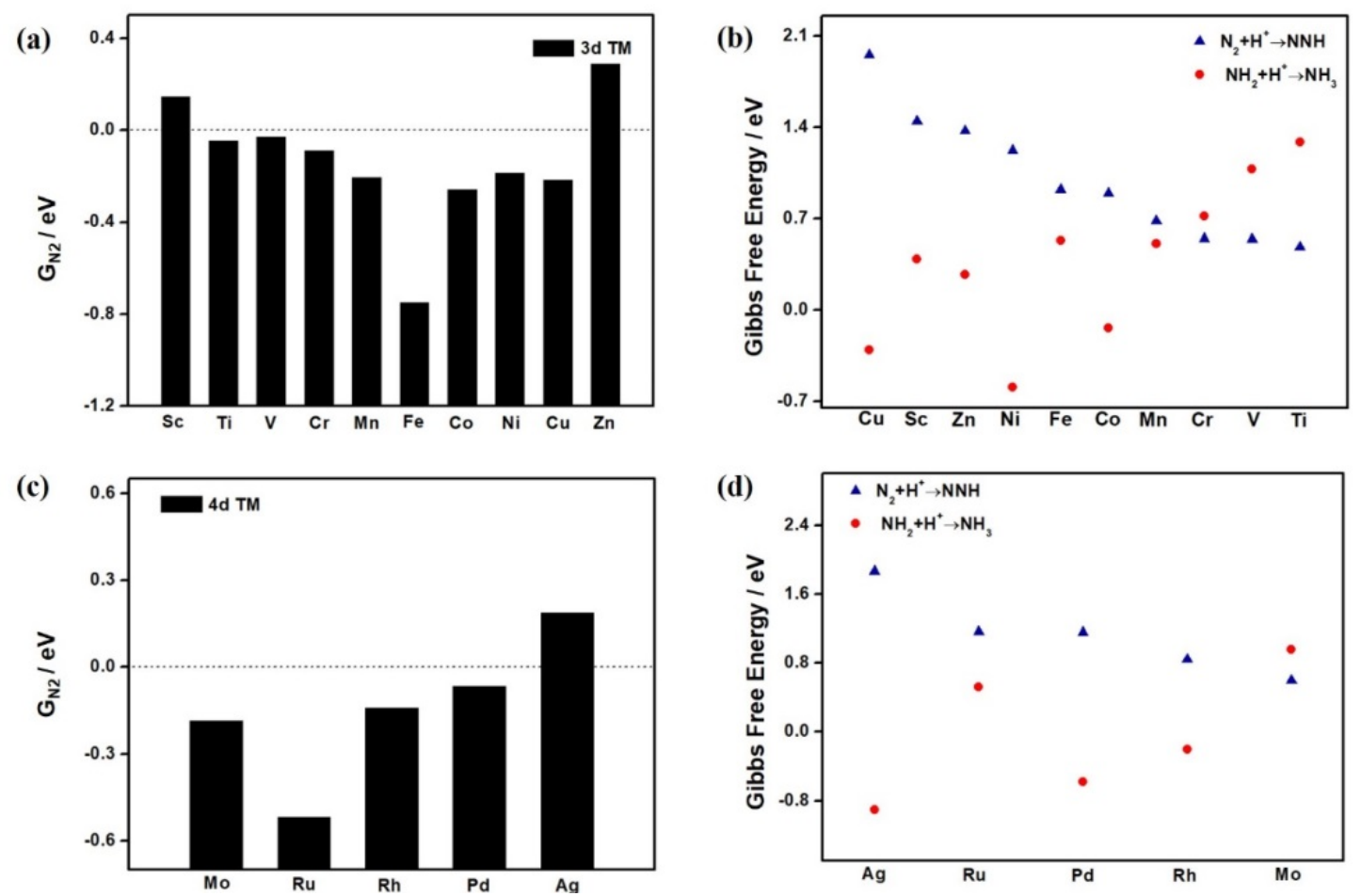

Fig. 6. The Gibbs free energies of $\mathrm{N}_{2}$ adsorption on the (a) $3 d$ and (b) late $4 d \mathrm{TM}$ atoms. The relationship between overpotential and Gibbs free energies of the (c) $3 d$ and (d) late $4 d$ TM atoms. 


\section{Graphical Abstract}

Chin. J. Catal., 2019, 40: 152-159 doi: 10.1016/S1872-2067(18)63197-3

\section{A theoretical study of electrocatalytic ammonia synthesis on single metal atom/MXene}

Yijing Gao, Han Zhuo, Yongyong Cao, Xiang Sun, Guilin Zhuang, Shengwei Deng, Xing Zhong, Zhongzhe Wei, Jian-guo Wang * Zhejiang University of Technology

The overpotential of electrolytic ammonia synthesis is determined by the Gibbs free energies of two potential-limiting steps $\mathrm{N}_{2}+\mathrm{H}^{+}$ $\rightarrow \mathrm{NNH}\left(\Delta G_{1}\right)$ and $\mathrm{NH}_{2}+\mathrm{H}^{+} \rightarrow \mathrm{NH}_{3}\left(\Delta G_{2}\right)$.

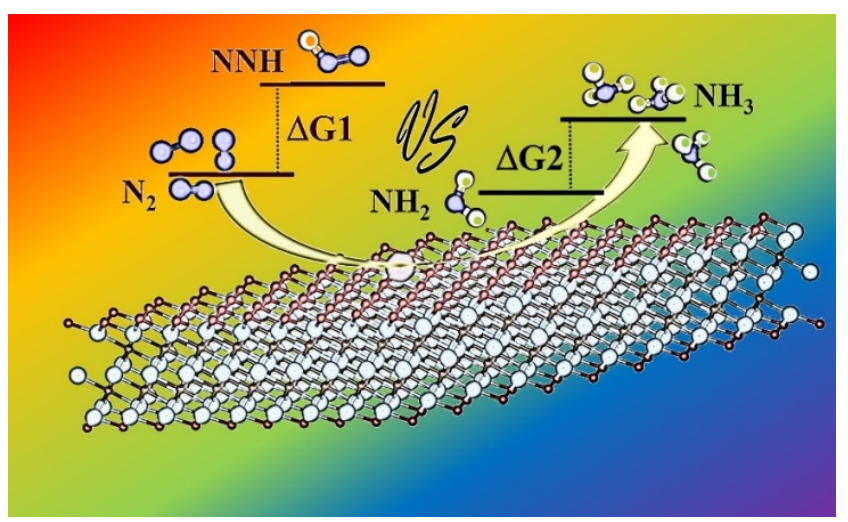

$\mathrm{NNH}$ and (ii) $\mathrm{NH}_{2}+\mathrm{H}^{+} \rightarrow \mathrm{NH}_{3}$. This work provides a new route for the rational designing and large-scale screening of these catalyst for electrocatalytic ammonia synthesis.

\section{References}

[1] T. Travis, Chem. Ind., 1993, 581-585.

[2] W. Patkowski, W. Rarog-Pilecka, Przem. Chem., 2017, 96, 1042-1046.

[3] J. H. Montoya, C. Tsai, A. Vojvodic, J. K. Norskov, ChemSusChem, 2015, 8, 2180-2186.

[4] I. A. Amar, R. Lan, C. T. G. Petit, S. Tao, J. Solid State Electrochem., 2011, 15, 1845-1860.

[5] V. Kyriakou, I. Garagounis, E. Vasileiou, A. Vourros, M. Stoukides, Catal. Today, 2017, 286, 2-13.

[6] B. H. R. Suryanto, C. S. M. Kang, D. B. Wang, C. L. Xiao, F. L. Zhou, L. M. Azofra, L. Cavallo, X. Y. Zhang, D. R. MacFarlane, ACS Energy Lett., 2018, 3, 1219-1224.

[7] Y. Abghoui, A. L. Garden, J. G. Howat, T. Vegge, E. Skulason, ACS Catal., 2016, 6, 635-646.

[8] Y. Abghoui, E. Skulason, Catal. Today, 2017, 286, 78-84.

[9] I. Coric, P. L. Holland, J. Am. Chem. Soc., 2016, 138, 7200-7211.

[10] J. G. Howalt, T. Bligaard, J. Rossmeisl, T. Vegge, Phys. Chem. Chem. Phys., 2013, 15, 7785-7795.

[11] Y. X. Chen, S. P. Chen, Q. S. Chen, Z. Y. Zhou, S. G. Sun, Electrochim. Acta, 2008, 53, 6938-6943.

[12] X. Zhang, D. F. Wu, D. J. Cheng, Electrochim. Acta, 2017, 246, 572-579.

[13] H. L. Dong, Y. Y. Li, D. E. Jiang, J. Phys. Chem. C, 2018, 122, 11392-11398.

[14] A. B. Hoskuldsson, Y. Abghoui, A. B. Gunnarsdottir, E. Skulason, ACS Sustain. Chem. Eng., 2017, 5, 10327-10333.

[15] J. Li, H. Zhou, H. Zhuo, Z. Wei, G. Zhuang, X. Zhong, S. Deng, X. Li, J. Wang, J. Mater. Chem. A, 2018, 6, 2264-2272.

[16] C. N. Cui, J. Y. Han, X. L. Zhu, X. Liu, H. Wang, D. H. Mei, Q. F. Ge, J. Catal., 2016, 343, 257-265.

[17] G. F. Chen, X. Cao, S. Wu, X. Zeng, L. X. Ding, M. Zhu, H. Wang, J. Am. Chem. Soc., 2017, 139, 9771-9774.

[18] A. N. A. Anasthasiya, M. Khaneja, B. G. Jeyaprakash, J. Electron. Mater., 2017, 46, 5642-5656.

[19] S. M. Chen, S. Perathoner, C. Ampelli, C. Mebrahtu, D. S. Su, G. Centi,
Angew. Chem. Int. Ed., 2017, 56, 2699-2703.

[20] F. Chen, X. Jiang, L. Zhang, R. Lang, B. Qiao, Chin. J. Catal., 2018, 39, 893-898.

[21] P. Hu, Z. Huang, Z. Amghouz, M. Makkee, F. Xu, F. Kapteijn, A. Dikhtiarenko, Y. Chen, X. Gu, X. Tang, Angew. Chem. Int. Ed., 2014, 53, 3418-3421.

[22] Y. B. Gu, X. L. Chen, Y. Y. Cao, G. L. Zhuang, X. Zhong, J. G. Wang, Nanotechnology, 2017, 28, 295403/1-295403/9.

[23] C. Zhang, W. Zhang, W. T. Zheng, Chin. J. Catal., 2018, 39, 4-7.

[24] X. B. He, F. X. Yin, H. Wang, B. H. Chen, G. R. Li, Chin. J. Catal., 2018, $39,207-227$.

[25] X. Y. Li, P. Cui, W. H. Zhong, J. Li, X. J. Wang, Z. W. Wang, J. Jiang, Chem. Commun., 2016, 52, 13233-13236.

[26] J. Zhao, J. X. Zhao, Q. H. Cai, Phys. Chem. Chem. Phys., 2018, 20, 9248-9255.

[27] Z. X. Wang, Z. G. Yu, J. X. Zhao, Phys. Chem. Chem. Phys., 2018, 20, 12835-12844.

[28] Y. Y. Cao, Y. J. Gao, H. Zhou, X. L. Chen, H. Hu, S. W. Deng, X. Zhong, G. L. Zhuang, J. G. Wang, Adv. Theory Simul., 2018, 1, 1870012.

[29] S. Back, J. Lim, N. Y. Kim, Y. H. Kim, Y. Jung, Chem. Sci., 2017, 8, 1090-1096.

[30] R. P. Pandey, K. Rasool, V. E. Madhavan, B. Aissa, Y. Gogotsi, K. A. Mahmoud, J. Mater. Chem. A, 2018, 6, 3522-3533.

[31] X. Zhang, J. C. Lei, D. H. Wu, X. D. Zhao, Y. Jing, Z. Zhou, J. Mater. Chem. A, 2016, 4, 4871-4876.

[32] X. Zhang, Z. H. Zhang, J. L. Li, X. D. Zhao, D. H. Wu, Z. Zhou, J. Mater. Chem. A, 2017, 5, 12899-12903.

[33] Y. J. Jiang, X. N. Zhang, L. J. Pei, S. Yue, L. Ma, L. Y. Zhou, Z. H. Huang, Y. He, J. Gao, Chem. Eng. J., 2018, 339, 547-556.

[34] L. Lorencova, T. Bertok, J. Filip, M. Jerigova, D. Velic, P. Kasak, K. A. Mahmoud, J. Tkac, Sensors Actuat. B, 2018, 263, 360-368.

[35] G. Y. Fan, X. J. Li, C. L. Xu, W. D. Jiang, Y. Zhang, D. J. Gao, J. Bi, Y. Wang, Nanomaterials, 2018, 8, 141/1-141/13.

[36] Y. Luo, G. F. Chen, L. Ding, X. Chen, L. X. Ding, H. Wang, Joule, 2018, DOI: 10.1016/j.joule.2018.09.021.

[37] J. Peng, X. Chen, W. J. Ong, X. Zhao, N. Li, Chem, 2018, 5, 1-33.

[38] G. Kresse, J. Furthmuller, Comp. Mater. Sci., 1996, pp. 15-50.

[39] G. Kresse, J. Furthmuller, Phys. Rev. B, 1996, 54, 11169-11186.

[40] J. P. Perdew, K. Burke, M. Ernzerhof, Phys. Rev. Lett., 1998, 80, 891-891.

[41] J. P. Perdew, K. Burke, M. Ernzerhof, Phys. Rev. Lett., 1996, 77, 3865-3868. 
[42] P. E. Blöchl, Phys. Rev. B, 1994, 50, 17953-17979.

[43] H. J. Monkhorst, J. D. Pack, Phys. Rev. B, 1976, 13, 5188-5192.

[44] S. Grimme, J. Antony, S. Ehrlich, H. Krieg, J. Chem. Phys., 2010, 132, 154104/1-154104/9.

[45] K. Momma, F. Izumi, J. Appl. Crystallogr., 2011, 44, 1272-1276.

[46] J. Rossmeisl, A. Logadottir, J. K. Nørskov, Chem. Phys., 2005, 319, 178-184.

[47] O. Mashtalir, M. Naguib, V. N. Mochalin, Y. Dall'Agnese, M. Heon, M. W. Barsoum, Y. Gogotsi, Nat. Commun., 2013, 4, 1716

[48] M. Naguib, M. Kurtoglu, V. Presser, J. Lu, J. Niu, M. Heon, L. Hultman, Y. Gogotsi, M. W. Barsoum, Adv. Mater., 2011, 23, 4248-4253.

[49] Y. Tong, M. He, Y. M. Zhou, X. Zhong, L. D. Fan, T. Y. Huang, Q. Liao, Y. J. Wang, J. Mater. Sci. Mater. Electron., 2018, 29, 8078-8088.
[50] L. Meng, Y. L. Wang, L. Z. Zhang, S. X. Du, R. T. Wu, L. F. Li, Y. Zhang, G. Li, H. T. Zhou, W. A. Hofer, H. J. Gao, Nano Lett., 2013, 13, 685-690.

[51] A. D. Becke, K. E. Edgecombe, J. Chem. Phys., 1990, 92, 5397-5403.

[52] W. Tang, E. Sanville, G. Henkelman, J. Phys. Condens. Matter., 2009, $21,7084204$.

[53] J. X. Zhao, Z. F. Chen, J. Am. Chem. Soc., 2017, 139, 12480-12487.

[54] L. M. Azofra, C. Sun, L. Cavallo, D. R. Macfarlane, Chem.-Eur. J., 2017, 23, 8275-8279.

[55] J. Rittle, J. C. Peters, J. Am. Chem. Soc., 2016, 138, 4243-4248.

[56] D. Bao, Q. Zhang, F. L. Meng, H. X. Zhong, M. M. Shi, Y. Zhang, J. M. Yan, Q. Jiang, X. B. Zhang, Adv. Mater., 2017, 29, doi: 10.1002/adma.2016014799.

\section{单原子负载型MXene用于电催化合成氨过程的理论计算}

高怡静, 卓 涵, 曹勇勇, 孙翔, 庄桂林, 邓声威, 钟 兴, 魏中哲, 王建国 浙江工业大学化学工程学院工业催化研究所实验室, 浙江杭州 310032

摘要: 合成氨在地球氮循环中扮演着重要角色. 工业上传统的合成氨方法采用高温高压的反应条件, 对反应设备要求高, 并且导致了巨大的能耗. 因此, 以电力为驱动的电催化合成过程作为一种新型的合成氨方法引起了广泛关注. 选择和设计 合适的催化剂以降低所需的过电势是该过程的一个重要研究课题. 常用的电催化剂包括金属基、金属氧化物、聚合物及 其他复合性催化剂. 其中, 单原子催化剂因其极高的原子利用率而广受关注, 但必须选择合适的基底使其成为兼具高催化 活性和高稳定性的催化剂. 二维过渡金属碳/氮化物(MXene)作为一种新型二维材料, 拥有和石墨烯类似的电导性质, 并与 金属有良好的相互作用, 是一种富有希望的载体. 本文采用密度泛函理论研究了氮气在一系列MXene负载的过渡金属单 原子催化剂上的吸附和活化, 通过吉布斯自由能计算研究了电催化合成氨的反应路径, 给出了相应的过电势. 同时, 通过 研究可能的决速步骤的吉布斯自由能, 分析了吉布斯自由能和过电势之间的关系.

计算结果表明, 在所有的MXene负载的过渡金属单原子上,氮气更倾向于一端吸附. 根据吉布斯自由能的定义,负值 显示这些催化剂具有良好的氮气活化性能, 特别是铁基催化剂 $(-0.75 \mathrm{eV})$, 这就不难理解工业上广泛应用铁基催化剂. 而负 载不同的过渡金属对电催化合成氨的过电势具有一定影响. 通过吉布斯自由能计算发现, 该系列金属的过电势在 0.68- $2.33 \mathrm{eV}, \mathrm{Mo} / \mathrm{Ti}_{3} \mathrm{C}_{2} \mathrm{O}_{2}$ 需要的外加电压最少. 这对实验上催化剂的选择具有一定的指导意义. 同时, 我们发现电催化合 成氨过程有两个可能的决速步骤: 氮气加氢生成 $N \mathrm{NH}$ 和 $\mathrm{NH}_{2}$ 生成氨气. 通过比较这两个步骤的吉布斯自由能可快速得到 催化剂的过电势.

因此, 我们可以得出结论, 该系列MXene负载的过渡金属单原子催化剂能够有效地改变反应路径, 免出现传统反应中 氮氮键断裂的巨大能垒, 从而有效降低了反应的过电势. 这为实验上选择合适的催化剂提供了理论依据. 并且, 这种通过 直接比较决速步骤的吉布斯自由能得到过电势的方法对电催化合成氨以及其他类似反应的催化剂篎选和理性设计具有指 导意义.

关键词: 电催化合成氨; 单原子催化剂; 二维过渡金属碳/氮化物(MXene); 过渡金属; 密度泛函理论; 过电势; 吉布斯自 由能

收稿日期: 2018-09-18. 接受日期: 2018-11-05. 出版日期: 2019-02-05.

*通讯联系人. 电话/传真: (0571)88871037; 电子信箱: jgw@zjut.edu.cn

基金来源：国家自然科学基金(21625604, 21776251, 21671172, 21706229, 21878272).

本文的电子版全文由Elsevier出版社在ScienceDirect上出版(http://www.sciencedirect.com/science/journal/18722067). 